
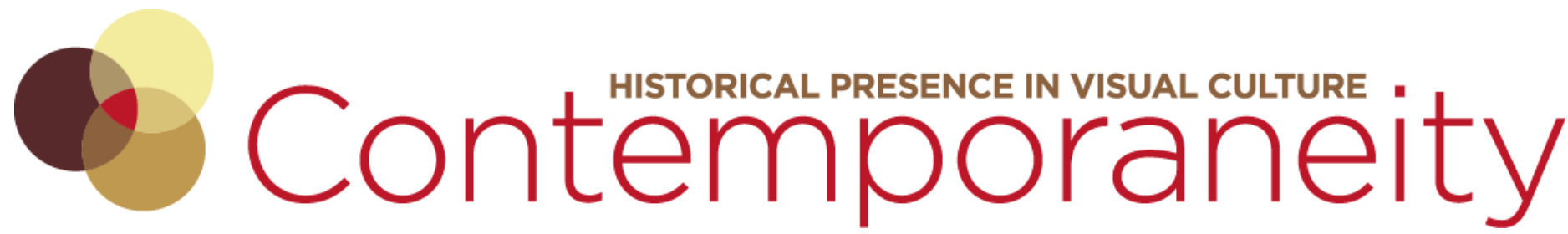

Vol 6, No 1 "Boundless" (2017) | ISSN 2153-5914 (online) | DOI 10.5195/contemp.2017.229 http://contemporaneity.pitt.edu

\title{
Fantasies of the Library Anna-Sophie Springer and Etienne Turpin, eds.
}

\section{Book Review}

Anna-Sophie Springer and Etienne Turpin, eds. Fantasies of the Library. Cambridge: The MIT Press, 2016. 160 pp.; 30 color ills.; 15 b/w ills. Hardcover \$24.95. (9780262035200)

\section{About the Author}

Chelsea Gunn is a doctoral student in Library and Information Science at the University of Pittsburgh's School of Computing and Information. She received her MLIS from Simmons College. Her research focuses on personal archives, digital preservation, and the technical and ethical challenges faced by archivists who collect born-digital networked personal records. 


\section{Fantasies of the Library}

It is relatively commonplace by now to see books and other information technologies used not only as means of researching exhibitions, but also as objects of focus in exhibitions themselves. Such treatment has a tendency to attend to the aesthetic or material qualities of books as discrete physical objects, separating them from the networks-shelves, catalogs, databases-in which they are generally found and from the intellectual processes by which information professionals make them accessible. In their collection, Fantasies of the Library, editors Anna-Sophie Springer and Etienne Turpin set out to position the reader as an exhibition viewer for an exploration of "the library as curatorial spaces - a physical knowledge infrastructure organized as the veritable index of cultural and epistemological orders and aspirations, but also as a virtual domain of possibilities for other orders, logics, and dispositions." ${ }^{1}$ These "possibilities" are to be read as the titular fantasies. Originally published as part of the Haus der Kulturen der Welt's intercalations: paginated exhibition, this book serves the series' agenda of critical reflection on contemporary curatorial practice, knowledge production, and information organization.

One of this book's main strengths is its framing of the processes of classification and arrangement not only alongside creative practice, but also as creative, interpretive endeavors in their own right. Throughout the essays, interviews, images, and letters that make up this volume are references to the often-invisible labor required to intellectually organize, physically arrange, and provide access to information both in person and online. Rather than positioning the book as a material or nostalgic object that stands in contrast to the seemingly ephemeral digital, the contributors throughout this collection emphasize the interconnected nature of the physical and digital, as well as the infrastructure required to sustain both. In this framing, the labor of information workers serves to connect and comingle the physical and digital, rather than pit them against one another. This relationship is perhaps exemplified most directly through Andrew Norman Wilson's ScanOps series, featured on the cover jacket and throughout the book. Wilson's collection of images, taken from the massive digitization project Google Books, features the hands of the digitizers encased in bright, unsettling latex finger cots or gloves, accidentally captured in the act of scanning or photographing a page. References like these, of the (sometimes literal) mark of the human hand, operate as a connecting thread through each of the pieces in Fantasies, underlining the editors' agenda of examining libraries and cultural collections as subjective, interpreted, and socially constructed spaces.

At the same time, the book's own organizational structure reinforces the reader-asexhibition-viewer perspective. A single essay, editor Springer's "Melancholies of the Paginated Mind: The Library as Curatorial Space," runs the full length of the book in serif typeface along the right-hand pages only, interrupted at the halfway point by Springer's visual essay "Reading Rooms Reading Machines," the book's full-color centerfold. The lefthand pages, in contrasting sans serif typeface, feature interviews with Megan Shaw Prelinger and Rick Prelinger of the Prelinger Library in San Francisco, Hammad Nasar of the Asia Art

\footnotetext{
${ }^{1}$ Anna-Sophie Springer and Etienne Turpin, Fantasies of the Library (Cambridge, MA: The MIT Press,
} 2016), iii. 
Archive in Hong Kong, and Joanna Zylinska, author of Minimal Ethics for the Anthropocene, as well as a letter from Charles Stankievech to the Superior Court of Quebec, written in defense of the online library and community platform arg.org. While it is technically true that any edited collection of essays may be read outside of the order set by the table of contents, the alternating pagination and unconventional layout of Fantasies essentially requires that they do. This arrangement has the potential to distract-but, as the editors note, this kind of "productive unruliness" also encourages the reader to actively engage with the text, charting her own navigational course through it.

Springer's "Melancholies of the Paginated Mind" establishes several of the book's primary themes: the subjective, interpretive nature of organizing information, the interplay between the intellectual classification and the arrangement of books in the physical environment, and the cultural roles and responsibilities of information spaces. Walking the reader through the real and imagined libraries of Borges, Warburg, Benjamin, and others, she offers case studies in various ways of seeing, classifying, and displaying books and other cultural artifacts. The visual essay "Reading Rooms Reading Machines" complements this work with forty-seven pages of depictions of libraries and other information infrastructures, including artist Katie Paterson's Future Library, The People's Library deployed during Occupy Wall Street, Donald Judd's personal library in Marfa, and book-scanning technologies.

These pieces work nicely as a scaffolding for the book, introducing areas of inquiry that reappear elsewhere. Alternative classification and the relationship between physical and digital points of access are further explored in Erin Kissane's interview with the Prelingers. Springer and Turpin's interview with Hammand Nasar unpacks the role of archival materials and collecting practices in shaping collective memory and the historical record, while their interview with Joanna Zylinska turns to the ethics and mechanics of book as a technology and a platform. Stankievich's letter in defense of arg.org, an online document-sharing platform accused of copyright infringement, presents the sharing of printed materials as beneficial not only to individuals seeking free and open access, but also to academic and publishing sectors more broadly. Viewing these sometimes complementary, sometimes contrasting narratives side-by-side in the book's alternating pagination brings that "productive unruliness" into play, juxtaposing divergent ideas within the reader's single field of vision.

Fantasies of the Library is an ambitious book. It critiques and interrogates the very forms it employs, but does so effectively, resulting in a creative tension that prompts the reader-as-exhibition-viewer to ask questions and seek additional resources. Each piece within it is densely packed with information and has the potential to spark further research. As a result, many parts of the book serve as jumping-off points for further questioning and resource-seeking rather than offering tidy conclusions. This composition ultimately feels fitting for a work grounded in information-seeking spaces and practices, and does not detract from the richness or quality of these narratives.

While this collection will likely appeal to a broad audience, a primary readership in the areas of art history, curatorial practice, and information science is easy to imagine. Readers coming from curatorial and information professions in particular will be pleased to see the ways in which the complex, creative work involved in collecting, arranging, and preserving cultural artifacts are made visible in this book. It will undoubtedly enhance the way its readers view book-based exhibitions move forward. Bringing together elements of history, philosophy, and literature, and connecting them to classification, curatorial practice, environmental ethics, academic publishing, and copyright, Fantasies of the Library effectively highlights the intersectional nature of libraries as socially constructed spaces. 
(cc) EY $^{\text {New }}$ articles in this journal are licensed under a Creative Commons Attribution 4.0 United States License.

\section{ULIS D-Sunt}

This journal is operated by the University Library System of the University of Pittsburgh as part of its D-Scribe Digital Publishing Program, and is co-sponsored by the University of Pittsburgh Press. 